\title{
Adubação fosfatada associada à cama de frango e sua influência na produtividade e no teor de flavonoides da Marcela (Achyrocline satureioides (Lam.) DC.) em duas épocas de colheita
}

\author{
VIEIRA, M.C. ${ }^{*}$; RAMOS, M.B.M. ${ }^{1 ;}$ HEREDIA ZÁRATE, N.A. ${ }^{1 ;}$ LUCIANO, A.T.'; GONÇALVES, W.V.'; \\ RODRIGUES, W.B. 1; TABALDI, L.A.2; CARVALHO, T.M. DE; SOARES, L.F. ${ }^{3}$; SIQUEIRA, J.M. DE ${ }^{3}$ \\ Universidade Federal da Grande Dourados - UFGD, Faculdade de Ciências Agrárias, Cx. Postal 533, 79804-

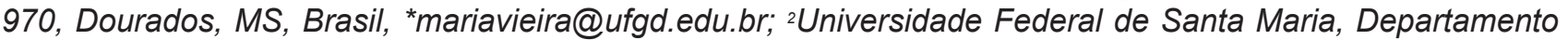 \\ de Biologia; '3niversidade Federal de São João Del Rei, Campus CCO - Dona Lindu, Divinópolis, MG, Brasil.
}

\begin{abstract}
RESUMO: Objetivou-se com este trabalho avaliar a produção de massa e o teor de flavonoides de plantas de marcela cultivadas com fósforo e cama de frango e colhidas em duas épocas. Estudou-se a combinação de doses de $\mathrm{P}_{2} \mathrm{O}_{5}\left(0,100,200\right.$ e $\left.300 \mathrm{~kg} \mathrm{ha}^{-1}\right)$ na forma de superfosfato triplo, com e sem cama de frango ( $10 \mathrm{tha}^{-1}$ ), arranjados como fatorial $4 \times 2$, no delineamento blocos casualizados, com quatro repetições. Foram feitas duas colheitas das plantas, consideradas como parcelas subdivididas no tempo. A propagação foi indireta, com semeio em bandejas e transplante ao campo. As plantas foram colhidas aos 195 e 223 dias após o transplantio - DAT. A altura máxima das plantas foi de 1,14 $\mathrm{m}$ com uso da cama de frango e de 0,97 $\mathrm{m}$ sem cama, aos 195 dias após o transplantio. A produção máxima de massa fresca de parte aérea das plantas foi de $30,31 \mathrm{t}^{-1}$ na colheita aos 223 DAT, enquanto a de massa seca foi de $11,38 \mathrm{t}$ ha-1, ambas com o uso de $300 \mathrm{~kg} \mathrm{ha}^{-1}$ de $\mathrm{P}_{2} \mathrm{O}_{5}$. A massa fresca de inflorescências foi maior $(4,08$ $\left.t \mathrm{tha}^{-1}\right)$ com adição de cama de frango ao solo e menor (3,49 $\left.\mathrm{tha}^{-1}\right)$ sem cama de frango; em resposta às doses de fósforo, cresceram linearmente, sendo a máxima de 4,65 tha-1 com uso de $300 \mathrm{~kg} \mathrm{ha}^{-1}$ de $\mathrm{P}_{2} \mathrm{O}_{5}$, independente da época de colheita. A massa seca de inflorescências foi máxima de 2,38 $\mathrm{t} \mathrm{ha}^{-1} \mathrm{com}$ o uso de $300 \mathrm{~kg}^{-1} \mathrm{P}_{2} \mathrm{O}_{5}$ na colheita aos 223 DAT. A maior produção de massa seca e o maior teor de flavonoides das inflorescências foram obtidos com o cultivo das plantas de marcela em solo com cama de frango $\left(10 \mathrm{t} \mathrm{ha}^{-1}\right)$ e com $\mathrm{P}_{2} \mathrm{O}_{5}\left(300 \mathrm{~kg} \mathrm{ha}^{-1}\right) \mathrm{na}$ colheita aos 223 dias após o transplantio.
\end{abstract}

Palavras-chave: Asteraceae, resíduo orgânico, fósforo, planta medicinal.

ABSTRACT: Total biomass and flavonoid contents of Achyrocline satureioides in response to phosphate fertilizer and broiler litter at two successive harvests. The aim of this experiment was to evaluate the biomass yield and flavonoid contents of Achyrocline satureioides grown under different levels of phosphate fertilizer in association with broiler litter, during two successive harvests. Four levels of $\mathrm{P}_{2} \mathrm{O}_{5}(0,100,200$ and $300 \mathrm{~kg} \mathrm{ha-1})$, as triple superphosphate, and two levels of broiler litter $\left(0\right.$ and $\left.10 \mathrm{tha}^{-1}\right)$ were arranged as a $4 \times 2$ factorial design in randomized blocks with four replications. Two harvests of plants, considered as splitplot, were made. Seeds were sown in polystyrene trays then transplanted to the experimental field and harvested at 195 and 223 days after transplanting (DAT). The maximum heights of the plants were $1.14 \mathrm{~m}$ under the addition of broiler litter and $0.97 \mathrm{~m}$ without it, at 195 days after transplanting. The highest yields of total fresh weight (30.31 ton ha-1) and dry weight (11.38 ton ha-1) were obtained at 223 DAT, both with the concentration of $300 \mathrm{~kg} \mathrm{ha}^{-1} \mathrm{P}_{2} \mathrm{O}_{5}$. The fresh weight of the inflorescences was greater under the addition of broiler litter ( 4.08 ton ha-1) than without it (3.49 ton ha-1). The plants grew linearly in response to the use of phosphate, and the maximum yield was 4.65 ton ha-1 under the concentration of $300 \mathrm{~kg} \mathrm{ha}^{-1} \mathrm{P}_{2} \mathrm{O}_{5}$, regardless of the harvest season. The dry weight of the inflorescences reached maximum yield ( 2.38 ton ha-1) at 223 DAT, in response to the use of $300 \mathrm{~kg} \mathrm{ha}^{-1} \mathrm{P}_{2} \mathrm{O}_{5}$. The highest yield of dry weight and the highest contents of flavonoids from the inflorescences were obtained when $A$. satureioides was grown under the concentration of $\mathrm{P}_{2} \mathrm{O}_{5}\left(300 \mathrm{~kg} \mathrm{ha}^{-1}\right)$ with the addition of broiler litter (10 ton ha-1) and harvested at 223 DAT.

Keywords: Asteraceae, organic manure, phosphorus, medicinal plant. 


\section{INTRODUÇÃO}

A marcela [Achyrocline satureioides (Lam.) DC., Asteraceae] é uma planta nativa da América do Sul, muito encontrada no Brasil, principalmente desde o estado de Minas Gerais até o Rio Grande do Sul, sendo conhecida também como macela, marcela-do-campo, camomila-nacional, dentre outros. Cresce espontaneamente em pastagens, beira de estradas e cerrado ralo. A planta é herbácea ou subarbustiva, ereta, medindo até $1,50 \mathrm{~m}$ de altura, com caule cilíndrico e tomentoso. Suas folhas são sésseis, lineares ou lanceoladas, com até 12 $\mathrm{cm}$ de comprimento e 1,8 $\mathrm{cm}$ de largura (Marques, 1998; Lorenzi \& Matos, 2002).

De todas as partes da planta de marcela, as mais utilizadas são as inflorescências secas, em capítulos numerosos, densos e agregados, as quais fazem parte da medicina popular brasileira e de outros países como Argentina, Uruguai e Paraguai (Fachinetto et al., 2007; Retta et al., 2012), sendo usadas na forma de infusos ou decoctos (Torres, 2005). Dentre os componentes químicos na marcela foram observados flavonoides, sesquiterpenos, monoterpenos e polissacarídeos imuno estimulantes (Broussalis et al., 1989; Puhlmann et al., 1992; Almeida et al., 1998; Lorenzi \& Matos, 2002; Leal et al., 2006; Holzschuh et al., 2010; Retta et al., 2011). Estudos farmacológicos comprovaram as propriedades digestiva, analgésica, antiulcerogênica gástrica, antiespasmódica, antiviral, anti-inflamatória e carminativa, dentre outras (Kadarian et al., 2002; Souza et al., 2007; Santin et al., 2010). Além disso, em muitas regiões do Brasil são usadas para o enchimento de travesseiros e acolchoados, em aromaterapia (Lorenzi, 2000).

A cama de frango é um resíduo orgânico de baixo custo em Mato Grosso do Sul e, pela sua composição química, vem sendo muito utilizada para suprir os nutrientes requeridos pelas plantas (Santos et al., 2004). É resultado do conjunto de maravalha, casca de arroz e palhadas, mas os conteúdos poderão variar dependendo do manejo, composição da alimentação e desperdício dos comedouros e bebedouros das aves (Konzen \& Alvarenga, 2006). O efeito dos resíduos orgânicos pode ser intensificado, principalmente quando associados com a adubação mineral (Fiorezi \& Ceretta, 2006).

Dentre os nutrientes essenciais para as plantas, o fósforo é um dos que merecem mais atenção em solos do Cerrado, onde esse elemento, em condições naturais, é muito baixo (Novais et al., 2007). O fósforo auxilia na definição da quantidade da biomassa produzida, podendo ainda contribuir para o aumento da concentração de alcalóides e demais princípios ativos. Seu déficit pode causar redução da biomassa e, consequentemente, dos metabólitos secundários (Martins et al., 1998; Taiz

\section{\& Zeiger, 2013).}

Poucos trabalhos foram encontrados na bibliografia consultada sobre os aspectos agronômicos da marcela (Retta et al., 2012); daí, a necessidade de se estudar tratos culturais, o que auxiliaria na preservação da espécie e da fonte de material cultivado para obtenção de futuros produtos fitoterápicos. Correa Júnior et al. (1994) citam que a marcela não tem exigências especiais em relação à adubação e recomendam a orgânica na dose $3,0 \mathrm{~kg} \mathrm{~m}^{-2}$ de esterco de curral ou composto orgânico, ou $1,5 \mathrm{~kg} \mathrm{~m}^{-2}$ de esterco de galinha. Outros experimentos (Davies, 1997) mostraram, no entanto, que a produtividade pode ser aumentada consideravelmente pela adubação nitrogenada quando a planta for cultivada em vasos. A massa seca das inflorescências poderia aumentar cerca de $45 \%$ com a adição do equivalente a $30 \mathrm{~kg} \mathrm{ha}^{-1}$ de $\mathrm{N}$ e de $122 \%$ com a adição de $60 \mathrm{~kg} \mathrm{ha}^{-1}$ de N. Leite et al. (2009) constataram que tanto o fósforo como a cama de frango tiveram efeito positivo no teor de flavonoides produzidos em marcela. Bottega et al. (2009) também descobriram que a qualidade do óleo essencial em marcela variou com a adição de resíduos orgânicos ou adubos fosfatados.

Considerando o valor das plantas medicinais não apenas como recurso terapêutico, mas, também, como fonte de recursos econômicos, tornase importante estabelecer linhas de ação voltadas para o desenvolvimento de técnicas de manejo ou cultivo. Dessa forma, o objetivo deste trabalho foi avaliar o crescimento, a produção de biomassa e o teor de flavonoides de plantas de marcela cultivadas com o uso de fósforo, na presença e ausência da cama de frango semidecomposta no solo.

\section{MATERIAL E MÉTODO}

O trabalho foi desenvolvido no Horto de Plantas Medicinais - HPM, da Universidade Federal da Grande Dourados - UFGD, em Dourados - MS, de abril de 2007 a abril de 2008. As coordenadas da área experimental são $22^{\circ} 11^{\prime} 43.7^{\prime \prime}$ de latitude sul, $54^{\circ} 56^{\prime} 08.5^{\prime \prime}$ de longitude oeste e altitude de $452 \mathrm{~m}$. O clima é classificado pelo Sistema Internacional de Köppen como Cwa, mesotérmico úmido. O solo da área experimental é classificado como Latossolo Vermelho distroférrico, de textura muito argilosa e de topografia plana, com as seguintes características químicas: $\mathrm{pH}$ em água $=4,7 ; \mathrm{pH}$ em $\mathrm{CaCl}_{2}=4,9$; matéria orgânica $=16,9 \mathrm{~g} \mathrm{~kg}^{-1} ; \mathrm{P}=20,0 \mathrm{mg} \mathrm{dm}^{-3} ; \mathrm{K}$ $=3,4 \mathrm{mmolc} \mathrm{dm}^{-3} ; \mathrm{Ca}=53,6 \mathrm{mmolc} \mathrm{dm}^{-3} ; \mathrm{Mg}=16,0$ mmolc dm ${ }^{-3} ; \mathrm{Al}=0,6$ mmolc dm$^{-3} ; \mathrm{H}+\mathrm{Al}=65,0 \mathrm{mmolc}^{-}$ $\mathrm{dm}^{-3} ; \mathrm{SB}=73,0 \mathrm{mmolc} \mathrm{dm}^{-3} ; \mathrm{T}=138,0 \mathrm{mmolc} \mathrm{dm}^{-3}$; $V=58,0 \%$, cujas determinações foram definidas segundo a metodologia proposta por Claessen

Rev. Bras. PI. Med., Campinas, v.17, n.2, p.246-253, 2015. 
(1997).

Os tratamentos corresponderam à combinação de quatro doses de $\mathrm{P}_{2} \mathrm{O}_{5}(0,100,200$ e $300 \mathrm{~kg} \mathrm{ha}^{-1}$ ), na forma de superfosfato triplo, com e sem cama de frango semidecomposta (10 t ha1), arranjados como fatorial $4 \times 2$, no delineamento blocos casualizados, com quatro repetições. Foram feitas duas colheitas das plantas, consideradas como parcelas subdivididas no tempo. Cada parcela tinha $3,0 \mathrm{~m}$ de comprimento $\times 1,0 \mathrm{~m}$ de largura, com seis plantas arranjadas em fileiras duplas, espaçadas de 0,50 m entre fileiras e entre plantas.

As sementes da marcela foram colhidas de plantas cultivadas no HPM, semeadas em abril de 2007, em bandejas de polietileno de 72 células, com substrato Plantmax $\mathrm{HA}^{\circledR}$ para hortaliças. No campo, o solo foi preparado com aração, gradagem e levantamento de canteiros com rotoencanteirador. A cama de frango e o superfosfato triplo foram aplicados a lanço e incorporados com o rotoencanteirador, um dia antes do transplantio das mudas. As características químicas da cama de frango foram: $C$ orgânico $=18,20$ dag kg-1; $P=$ 0,89 dag $\mathrm{kg}^{-1} ; \mathrm{K}=0,59$ dag $\mathrm{kg}^{-1} ; \mathrm{N}=2,01 \mathrm{dag} \mathrm{kg}^{-1}$; $\mathrm{Ca}=6,56$ dag kg-1$^{-1} ; \mathrm{Mg}=0,57$ dag kg-1 $^{-1}$ e Relação $\mathrm{C} / \mathrm{N}$ $=9 / 1$. O transplantio ao campo foi feito quando as plântulas apresentavam cerca de $15 \mathrm{~cm}$ de altura, 0 que ocorreu aos 70 dias após a semeadura.

O controle de plantas infestantes foi feito com enxada. As irrigações foram feitas utilizando o sistema de aspersão, sendo que na fase inicial, até as plantas apresentarem entre 15 e $30 \mathrm{~cm}$ de altura, os turnos de rega foram a cada dois dias; daí, até o final do ciclo, as regas foram a cada três ou quatro dias. Não foram feitos controles fitossanitários porque não houve ocorrência de pragas nem de doenças.

Durante o ciclo de cultivo foram medidas as alturas de todas as plantas $(\mathrm{cm})$ a partir de 60 até 195 dias após o transplantio (DAT), com intervalo de 15 dias, como medidas repetidas no tempo. Foram feitas duas colheitas das plantas, sendo a primeira aos 195 e a segunda aos 223 DAT. Em cada uma delas foram colhidas quatro plantas por parcela, as quais foram cortadas rente ao solo. No laboratório de pós-colheita, foram separadas as inflorescências e as partes aéreas das plantas, sendo pesadas para obtenção das massas frescas. Depois, as partes aéreas foram cortadas e todo o material foi colocado em estufa com circulação forçada de ar a $38 \pm 2{ }^{\circ} \mathrm{C}$ até massa constante, para obtenção da massa seca. Após a determinação da massa seca, parte do material das folhas das plantas da segunda época de colheita foram utilizadas para determinação do teor de fósforo no tecido foliar (Malavolta, 2006).

Os dados foram submetidos à análise de variância e quando houve significância pelo teste $F$, os dados em função de dias após o transplantio e de fósforo foram submetidos à análise de regressão $(p<0,05)$.

O doseamento de flavonoides totais foi realizado nas inflorescências de todos os tratamentos, conforme método proposto pela Associação Federal Alemã de Medicamentos (Deutsches Arzneimittel Bundesvereinigung,1986). Pesaram-se $400 \mathrm{~g}$ do pó da droga vegetal, sendo estes transferidos para um balão de fundo redondo de $100 \mathrm{~mL}$. Foi acrescentado ao balão $1,0 \mathrm{~mL}$ de metanamina $0,5 \%(\mathrm{~m} / \mathrm{v}) ; 20,0 \mathrm{~mL}$ de acetona e $2,0 \mathrm{~mL}$ de ácido clorídrico. A mistura foi submetida a refluxo com aquecimento de banho de água por 30 minutos e filtrada em algodão, para um balão volumétrico de $100 \mathrm{~mL}$. O resíduo da filtração e o algodão foram colocados novamente no balão de fundo redondo e lavados com duas porções de 20,0 $\mathrm{mL}$ de acetona sob refluxo por 10 minutos. Após arrefecer à temperatura ambiente, as soluções foram filtradas através de algodão para o balão volumétrico de $100 \mathrm{~mL}$, completando-se o volume com acetona. Em um funil de separação, uma alíquota de $20 \mathrm{~mL}$ da solução foi acrescida de $20 \mathrm{~mL}$ de água e extraídos com $15 \mathrm{~mL}$ de acetato de etila. A extração foi repetida três vezes com porções de $10 \mathrm{~mL}$ de acetato de etila.

As fases acetato de etila foram reunidas $e$ lavadas com duas porções de $50 \mathrm{~mL}$ de água em um funil de separação, sendo em seguida reunidas em um balão volumétrico de $50 \mathrm{~mL}$, completandose o volume com acetato de etila, recebendo a denominação de solução mãe. Para a preparação da solução amostra, uma alíquota de $10 \mathrm{~mL}$ da solução mãe foi acrescida de $1,0 \mathrm{~mL}$ de solução metanólica de cloreto de alumínio $2 \%(\mathrm{~m} / \mathrm{v})$, sendo diluída com solução metanólica de ácido acético $5 \%(\mathrm{v} / \mathrm{v})$ em balão volumétrico de $25 \mathrm{~mL}$. Para preparar a solução comparativa, uma alíquota de $10 \mathrm{~mL}$ da solução mãe foi diluída com solução metanólica de ácido acético $5 \%$ (v/v) em balão volumétrico de $25 \mathrm{~mL}$.

A absorvância da solução amostra foi medida utilizando a solução comparativa como branco (solvente) e padrão (quercetina Aldrich), em cubeta de $1 \mathrm{~cm}$ de caminho óptico, 30 minutos após a adição de cloreto de alumínio. A leitura foi feita no comprimento de onda de $425 \mathrm{~nm}$.

Os testes foram realizados em triplicata e expressos em percentual (C), calculados em quercetina, segundo a equação: $\mathrm{C}=\mathrm{A}$. $\mathrm{fd} / 500$. m . $(100-\mathrm{pd})$; em que $\mathrm{C}=$ percentual de flavonoides totais $(\mathrm{m} / \mathrm{m}) ; A=$ absorvância medida (AUFS); $f d=$ fator de diluição; $m=$ massa da droga $(g) ; p d=$ perda por dessecação da matéria - prima vegetal $(\% ; \mathrm{m} / \mathrm{m})$.

Para a determinação da perda por dessecação foram pesadas aproximadamente $3,0 \mathrm{~g}$ das amostras pulverizadas, as quais,

Rev. Bras. PI. Med., Campinas, v.17, n.2, p.246-253, 2015. 
após a pesagem, foram colocadas em estufa, à temperatura de $105^{\circ} \mathrm{C}$, por 5 horas. Ao resfriar as amostras no dessecador, as mesmas foram novamente pesadas e colocadas de volta à estufa por mais uma hora. O procedimento foi repetido até que as amostras atingissem massa constante (Farmacopéia Brasileira, 2010). Com as médias das três determinações, os resultados foram expressos em perda de massa percentual.

Os dados obtidos no doseamento foram submetidos à análise de variância e as médias foram comparadas entre si, pelo teste de Tukey $(p<0,05)$.

\section{RESULTADO E DISCUSSÃO}

As alturas das plantas da marcela foram influenciadas significativamente apenas pela cama de frango, apresentando curvas de crescimento cúbicas, sendo as plantas mais altas aquelas cultivadas com a cama de frango (Figura 1). Até aos 90 dias após o transplantio, o crescimento foi lento e depois o incremento na altura foi rápido, coincidindo com o período de emissão dos pendões florais. $O$ uso da cama de frango resultou em altura máxima de 1,14 m, comparados com 0,97 m sem cama, aos 195 dias após o transplantio. A maior altura das plantas com o uso da cama de frango permite supor que houve melhoria das propriedades físicas e biológicas do solo, além de corrigir possíveis deficiências de macro e micronutrientes no solo, que podem ter favorecido o crescimento das plantas (Kiehl, 2010).

Houve interação significativa entre doses de fósforo e colheitas sobre a produção de massa fresca das partes aéreas das plantas de marcela. Na primeira colheita, as produções foram independentes das doses de fósforo e foram, em média, de 24,5 t ha-1 (Figura 2 e Tabela 1). $\mathrm{Na}$ segunda colheita, apresentaram crescimento linear positivo com taxas crescentes e diretamente relacionadas com as doses de fósforo adicionadas ao solo, tendo-se produção máxima de $30,31 \mathrm{t} \mathrm{ha}^{-1}$ com o uso de $300 \mathrm{~kg} \mathrm{ha}^{-1} \mathrm{P}_{2} \mathrm{O}_{5}$. A cama de frango não influenciou a produção de massa fresca de parte aérea da marcela.

As massas secas das partes aéreas foram influenciadas significativamente pelos efeitos isolados do fósforo, da cama de frango e das colheitas. Apresentaram crescimento linear positivo com taxas diretamente relacionadas com as doses de $\mathrm{P}_{2} \mathrm{O}_{5}$ adicionadas ao solo, sendo a produção máxima de 11,38 t ha-1 com o uso de $300 \mathrm{~kg}^{-1}$ $\mathrm{P}_{2} \mathrm{O}_{5}$ (Figura 2). A maior produção da parte aérea da marcela em resposta à adição de fósforo ao solo pode ter relação com a função do nutriente nos processos metabólicos das plantas, como divisão celular, respiração e como regulador de fósforo inorgânico na fotossíntese (Taiz \& Zeiger, 2013). Com adição da cama de frango ao solo as massas

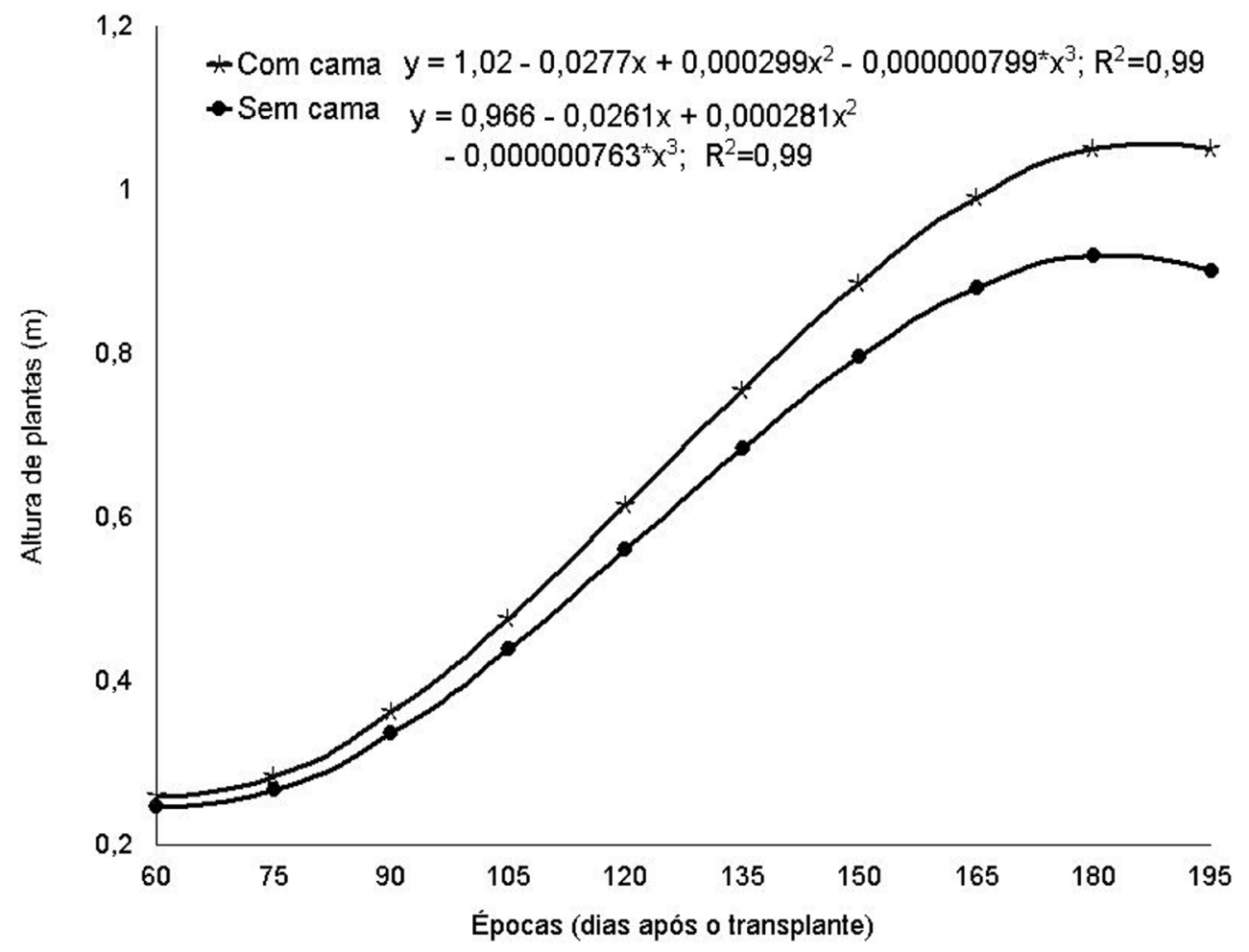

FIGURA 1. Altura de plantas de marcela em função de dias após o transplantio, cultivadas sem ou com cama de frango. Dados em função de fósforo foram agrupados. 


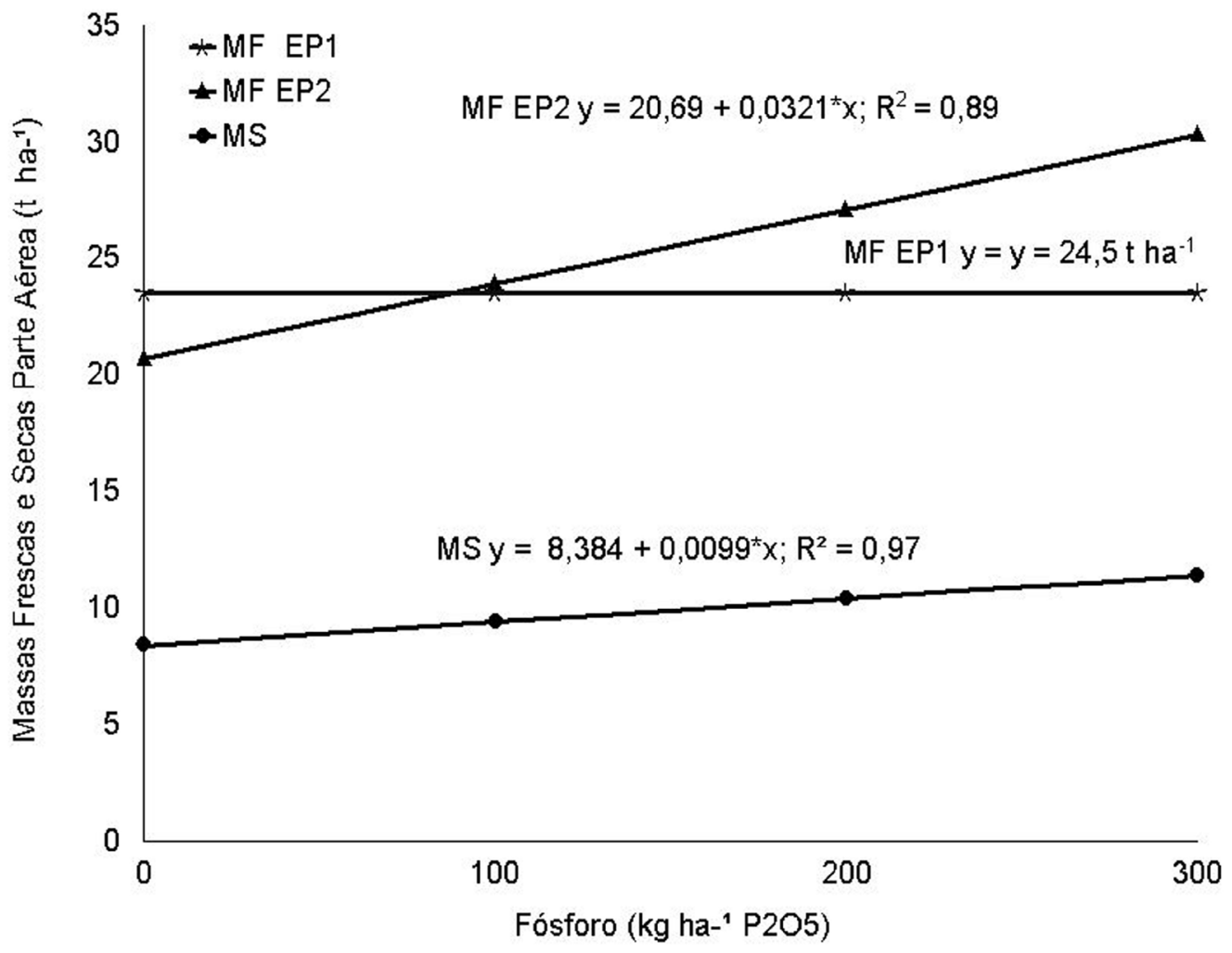

FIGURA 2. Massas frescas (MF) e secas (MS) das partes aéreas das plantas de marcela em função de doses de fósforo, em duas épocas de colheita, aos 195 (EP1) e 223 (EP2) dias após o transplantio - DAT. Os dados em função de cama de frango foram agrupados.

TABELA 1. Massa fresca (MF) de inflorescências e massas frescas e secas (MS) da parte aérea de plantas de marcela cultivadas sem ou com uso de cama de frango semidecomposta.

\begin{tabular}{lccc}
\hline & MF Parte Aérea & MS Parte Aérea & MF Inflorescência \\
\hline & & t ha-1 & \\
Sem cama de frango & $24,23 \mathrm{a}$ & $9,20 \mathrm{~b}$ & $3,49 \mathrm{~b}$ \\
Com cama de frango & $24,80 \mathrm{a}$ & $10,56 \mathrm{a}$ & $4,08 \mathrm{a}$ \\
C.V. $(\%)$ & 16,6 & 21,4 & 18,1 \\
\hline
\end{tabular}

Médias seguidas por letras diferentes nas colunas diferem entre si pelo teste $\mathrm{F}$, a $5 \%$ de probabilidade.

secas das partes aéreas superaram em $12,88 \%$ às produções das plantas cultivadas em solo sem adição de cama de frango. O efeito da cama de frango pode ser pelo fato de a incorporação da matéria orgânica no solo poder provocar intensa atividade dos micro-organismos, fazendo com que as substâncias produzidas funcionem como elementos aglutinantes das partículas, melhorando a estruturação do solo (Kiehl, 2010) e assim as raízes puderam se desenvolver melhor em diâmetro e profundidade.

Gassi et al. (2009), ao estudarem o efeito do uso de $\mathrm{P}_{2} \mathrm{O}_{5}(4,3 ; 25,8 ; 43,0 ; 60,2$ e $81,7 \mathrm{~kg}$ ha1) e da cama de frango (1, 6, 10, 14 e $\left.19 \mathrm{t} \mathrm{ha}^{-1}\right) \mathrm{na}$ produção da bardana (Arctium lappa L.), espécie medicinal da mesma família da marcela, verificaram que as maiores produções de massa fresca das folhas foram de $22,87 \mathrm{t} \mathrm{ha}^{-1}$, quando se utilizou
$81,7 \mathrm{~kg} \mathrm{ha}^{-1}$ de $\mathrm{P}_{2} \mathrm{O}_{5}$ e de $18,38 \mathrm{tha}^{-1} \mathrm{com}$ a dose de $19 \mathrm{t} \mathrm{ha}^{-1}$ de cama de frango e as maiores massas secas das folhas ocorreram sob as maiores doses de cama de frango.

Com relação às colheitas, foi observado que na colheita aos 195 DAT, a massa seca da parte aérea foi, em média, de 10,41 t ha-1 e aos 223 DAT foi de 9,36 tha-1. A menor massa seca na segunda colheita deveu-se à maior senescência da parte aérea das plantas, em relação à primeira colheita.

As massas frescas das inflorescências das plantas de marcela foram influenciadas significativamente pelos efeitos isolados do fósforo e da cama de frango, mas foram semelhantes nas duas colheitas. Plantas cultivadas com cama de frango tiveram $14,46 \%$ mais produção de inflorescências do que aquelas sem cama de frango (Tabela 1). Com relação ao fósforo, a produção cresceu linearmente 
em resposta ao nutriente (Figura 3), sendo a máxima de 4,65 tha-1 com uso de $300 \mathrm{~kg} \mathrm{ha}^{-1} \mathrm{P}_{2} \mathrm{O}_{5}$. Por outro lado, as massas secas das inflorescências foram influenciadas pelas interações fósforo e cama de frango e fósforo e colheitas (Figura 3). A massa seca média em função de fósforo, na presença de cama de frango, foi de 2,08 tha-1. Na ausência da cama de frango e com o aumento das doses de fósforo, a máxima produtividade foi de $2,05 \mathrm{t} \mathrm{ha}^{-1}$. Quanto às colheitas, aos 195 DAT, a massa seca média foi de $1,71 \mathrm{t} \mathrm{ha}^{-1}$, enquanto aos 223 DAT a massa seca máxima foi de $2,38 \mathrm{t} \mathrm{ha}^{-1}$, com uso de $300 \mathrm{~kg}$ ha-1 $\mathrm{P}_{2} \mathrm{O}_{5}$.

Os resultados obtidos para as massas frescas (Tabela 1 e Figura 3 ) e as massas secas (Figura 3) das inflorescências das plantas de marcela podem ter relação com os prováveis efeitos benéficos dos adubos mineral fosfatado e do adubo orgânico que podem ter aumentado o fósforo disponível para as plantas e que, segundo Amorim et al. (2008), esse nutriente passa a ser um daqueles com maior resposta pelas plantas. Consequentemente, o cultivo adequado nesses solos tem, na fertilização fosfatada, técnica eficiente para aumentar a produtividade, favorecendo o desenvolvimento do sistema radicular, aumentando a absorção de água e de nutrientes, e, como consequencia, a qualidade e o rendimento dos produtos colhidos (Novais et al., 2007). Também, Barboza et al. (2009), trabalhando com calêndula, planta medicinal da mesma família da marcela, concluíram que para maior produção de capítulos florais, componente de maior importância comercial, a calêndula deve ser cultivada com adubo mineral fosfatado em associação com a cama de frango.

Apenas a adubação fosfatada influenciou o teor de fósforo foliar, que aumentou linearmente $(\hat{y}$ $\left.=0,48133+0,0002298^{*} x ; R^{2}=0,99\right)$ com as doses de fósforo aplicadas ao solo, sendo o teor máximo de $0,55 \mathrm{~g} \mathrm{~kg}^{-1}$ observado com uso de $300 \mathrm{~kg} \mathrm{ha}^{-1}$ de $\mathrm{P}_{2} \mathrm{O}_{5}$. A maior absorção de fósforo se refletiu em maior produção de massa seca e fresca da parte aérea e de inflorescências (Figuras 2 a 3).

Em geral, as amostras que apresentaram o maior percentual de flavonoides totais foram das inflorescências de plantas cultivadas sem cama de frango (Tabela 2), exceto a amostra de plantas cultivadas com $100 \mathrm{~kg} \mathrm{ha}^{-1}$ de $\mathrm{P}_{2} \mathrm{O}_{5}$ e $10 \mathrm{t}$ ha-1 de cama. As amostras sem $\mathrm{P}_{2} \mathrm{O}_{5}$ e com cama de frango; $200 \mathrm{~kg}^{\text {ha-1 }} \mathrm{P}_{2} \mathrm{O}_{5}$ sem cama de frango, $200 \mathrm{~kg} \mathrm{ha}{ }^{-1} \mathrm{P}_{2} \mathrm{O}_{5}$ com cama de frango e $300 \mathrm{~kg} \mathrm{ha}^{-1}$ $\mathrm{P}_{2} \mathrm{O}_{5}$ com cama de frango apresentaram valores de flavonoides totais equivalentes em quercetina inferiores ao especificado na Farmacopéia Brasileira

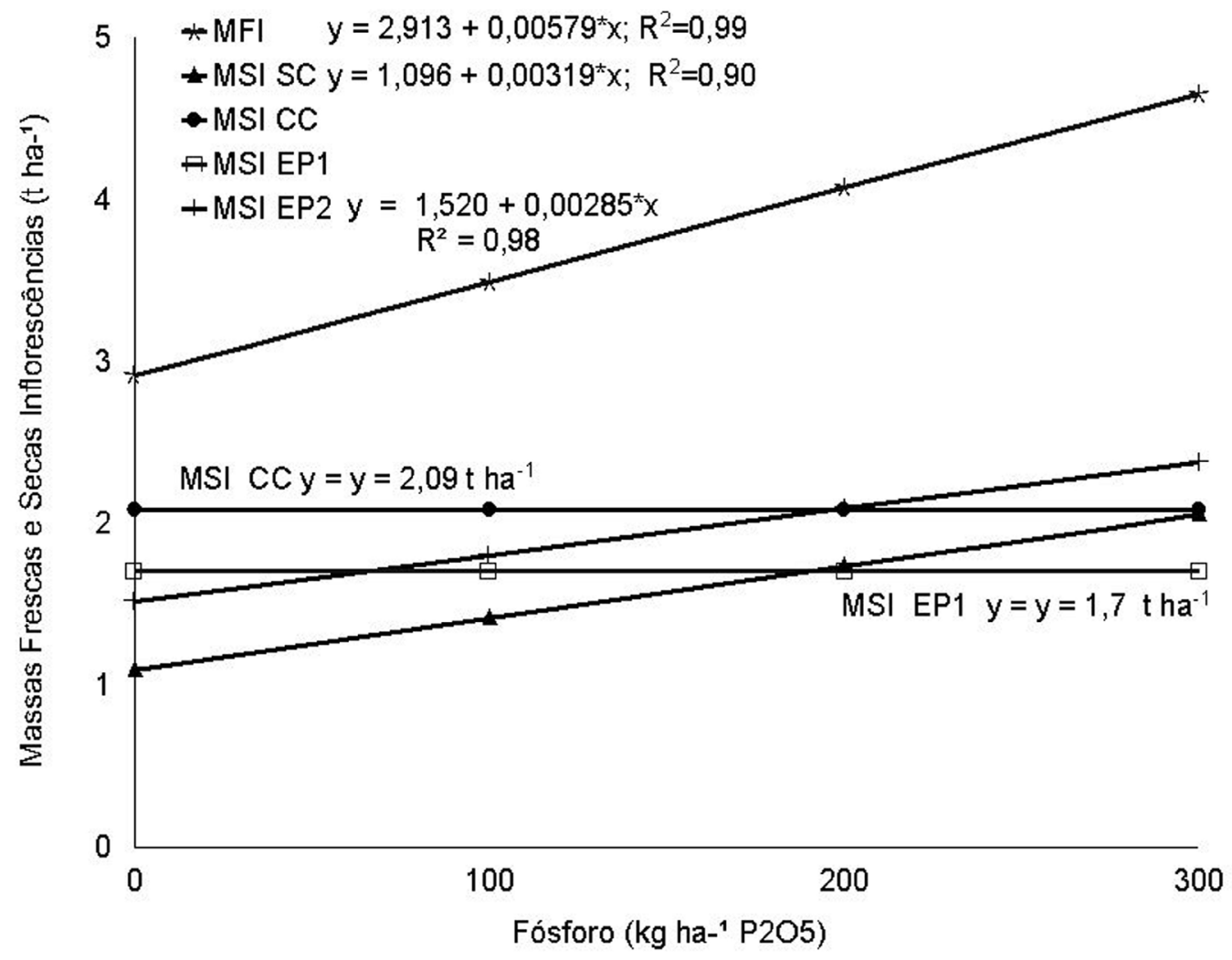

FIGURA 3. Massas frescas (MFI) e secas (MSI) das inflorescências das plantas de marcela em função de doses de fósforo, sem ou com o uso de cama de frango, com colheitas aos 195 (EP1) e 223 (EP2) dias após o transplantio - DAT. 
TABELA 2. Quantificação espectrofotométrica do percentual de flavonoides totais $(\mathrm{m} / \mathrm{m})$, em $425 \mathrm{~nm}$, para as amostras de inflorescências de marcela cujas plantas foram cultivadas com diferentes doses de $\mathrm{P}_{2} \mathrm{O}_{5}$ e cama de frango.

\begin{tabular}{lcc}
\hline $\mathrm{P}_{2} \mathrm{O}_{5}\left(\mathrm{~kg} \mathrm{ha}^{-1}\right)$ & $\begin{array}{c}\text { Cama de frango } \\
(10 \mathrm{t} \mathrm{ha}-1)\end{array}$ & $\begin{array}{c}\mathrm{C} \pm \mathrm{DP}(\% ; \mathrm{m} / \mathrm{m})^{\star} \\
\text { Flavonoides totais }\end{array}$ \\
\hline 0 & Sem & $1,80 \mathrm{a} \pm 0,0285$ \\
0 & Com & $1,14 \mathrm{~d} \pm 0,0483$ \\
100 & Sem & $1,75 \mathrm{a} \pm 0,0540$ \\
100 & Com & $1,80 \mathrm{a} \pm 0,0035$ \\
200 & Sem & $1,08 \mathrm{e} \pm 0,0185$ \\
200 & Com & $1,63 \mathrm{~b} \pm 0,0509$ \\
300 & Sem & $1,85 \mathrm{a} \pm 0,0089$ \\
300 & Com & $1,32 \mathrm{c} \pm 0,0035$ \\
\hline
\end{tabular}

* Os valores com as mesmas letras não diferem entre si, a 5\% de significância, pelo teste de médias. DP= Desvio padrão da média.

$4^{\mathrm{a}}$ edição, a qual preconiza que o percentual mínimo de flavonoide total calculado em quercetina deve ser de $1,7 \%$.

As tentativas de adubação com nitrogênio, fósforo, cama de frango e outros tratamentos sempre aventam a possibilidade de uma reposta no teor de princípio ativo (P.A.) (Retta et al., 2012). Para a marcela, foi desenvolvido um procedimento semelhante e observou-se a mesma relação apresentada no presente trabalho, ou seja, os teores dos princípios ativos nas inflorescências das plantas submetidas aos diferentes tratamentos foram bastante próximos da testemunha (Leite et al., 2009).

O teor de um metabólito secundário (P.A.) em uma espécie vegetal é ainda bastante controverso e sabe-se que sofre influência de diversos fatores biológicos e ambientais (Gouvea et al., 2012). Em experimentos controlados com Plantago lanceolata, envolvendo testes com teores diferentes de nutrientes e a presença de predador herbívoro, demonstrou-se a capacidade de essa espécie vegetal produzir maior quantidade de metabólito secundário responsável pela defesa contra a herbivoria (Darrow \& Bowers, 1999). Teores de substâncias fenólicas, por exemplo, são bastante influenciados pela incidência de irradiação solar sobre a espécie, que aumenta em períodos chuvosos (Gouvea et al., 2012), dentre eles flavonoides, que podem estar implicados com a foto-proteção (Gobbo-Neto e Lopes, 2007).

\section{CONCLUSÕES}

Nas condições em que foi desenvolvido o experimento, a maior produção de massa seca e teor de flavonoides das inflorescências foi obtido com o cultivo das plantas de marcela em solo com cama de frango (10 $\left.\mathrm{t} \mathrm{ha}^{-1}\right)$ e fósforo $\left(300 \mathrm{~kg} \mathrm{ha}^{-1} \mathrm{P}_{2} \mathrm{O}_{5}\right) \mathrm{e}$ colheita aos 223 dias após o transplante.

\section{AGRADECIMENTOS}

Ao CNPq, pela bolsa de IC ao TMC, Edital MCT/CNPq 12/2010. Os autores MCV, NAHZ e JMS agradecem ao CNPq pela Bolsa Produtividade em Pesquisa. Os autores são também gratos à FAPEMIG, pelo recurso para pesquisa (Grant) dentro do projeto PPM-00108-11 e à FUNDECT, pelos recursos financeiros.

\section{REFERÊNCIAS}

ALMEIDA, S. P. de. et al. Cerrado: espécies vegetais úteis. Planaltina: EMBRAPA-CPAC, 1998. 464 p.

AMORIM, L.B. et al. Disponibilidade de fósforo em Neossolo quartzarênico cultivado com melão. Caatinga, Mossoró, v.21, n.3, p.141-146, 2008.

BARBOZA, V.C. et al. Produção de biomassa de Calendula officinalis L. adubada com fósforo e cama de frango. Ciência e Agrotecnologia, Lavras, v.33, n.2, p.478-483, 2009.

BOTTEGA, F.C. et al. Influência de tratamentos agronômicos na produção de óleos essenciais em Achyrocline satureioides. In: Reunião Anual da Sociedade Brasileira de Química, 32. Resumos... Fortaleza, brasil.

BROUSSALIS, A.M. et al. Aspectos fitoquímicos de especies argentinas del género Achyrocline. Latin American Journal of Pharmacy, Buenos Aires, v.8, n.1, p.11-16, 1989.

DEUTSCHES ARZNEIMITTEL BUNDESVEREINIGUNG (Hgrs.). Deutscher Arzneimittel - Codex. Frankfurt: Govi, Stuttgart: Deutscher Apotheker, 1086. v. 2: Holunderbluten, p. 1-3. 1986.

CLAESSEN, M.E.C. Manual de métodos de análises de solo. 2.ed. Rio de Janeiro: EMBRAPA-CNPS, 1997. 212p. (EMBRAPA-CNPS. Documentos, 1).

CORREA JÚNIOR, C. et al. Cultivo de plantas medicinais, condimentares e aromáticas. UNESP: Botucatu, 1994. 162 p.

DARROW, K; BOWERS, D. Effects of herbivore damage and nutrient level on induction of iridoid glycoside in Plantago lanceolata. Journal of Chemical Ecology , 
New York, v. 25, p. 1427-1440, 1999.

DAVIES, P. Experimentation on cultivation of Achyrocline flaccida Weinm. and Achyrocline satureioides (Lam.) D.C. in Uruguay. Acta Horticulturae, Mendoza, n. 502, p. 59-66, 1997.

FACHINETTO, J.M. et al. Efeito anti-proliferativo das infusões de Achyrocline satureioides DC (Asteraceae) sobre o ciclo celular de Allium cepa. Revista Brasileira de Farmacognosia, Curitiba, v.17, p.49-54, 2007.

FARMACOPÉIA Brasileira. 5. ed., v. 1. Brasília: Agência Nacional de Vigilância Sanitária, 2010.

GASSI, R.P. et al. Doses de fósforo e de cama-de-frango na produção de bardana. Ciência e Agrotecnologia, Lavras, v.33, n.3, p.692-697, 2009.

GOBBO-NETO, L, LOPES, N. P. Plantas medicinais: Fatores de influência no conteúdo de metabólitos secundários. Química Nova, São Paulo, v. 30, p. 374381, 2007.

GOUVEA, D. R. et al. Seasonal variation of the major secondary metabolites present in the extract of Eremanthus mattogrossensis Less (Asteraceae: Vernonieae) leaves. Química Nova, São Paulo, v. 35, p. 2139-2145, 2012.

KADARIAN, C.E. et al. Hepatoprotective activity of Achyrocline satureioides (Lam.) DC. Pharmacological Research, Netherlands, v.45, n.1, p.57-61, 2002.

KIEHL, E. J. Novos fertilizantes orgânicos. 1. ed. Piracicaba-SP: Degaspari,. 2010. 248 p.

KONZEN, E. A.; ALVARENGA, R. C. Cultivo do milho. Adubação orgânica. Embrapa Milho e Sorgo. Sistemas de Produção 1. Versão eletrônica. Dezembro 2006. Available at: <htpp://www.sistemasdeproducao.cnptia. embrapa.br>. Accessed on 31 January 2011.

LEAL, P. et al. Global yields, chemical compositions, and antioxidant activities of extracts from Achyrocline alata and Achyrocline satureioides. Pharmacognosy Magazine, Índia, v.2, n.7, p. 153-159, 2006.

LEITE, C.M.B. et al. Avaliação de flavonoides e atividade antioxidante em Achyrocline satureioides cultivadas com adição de cama-de-frango e fósforo. In: In: Reunião Anual da Sociedade Brasileira de Química, 32. Resumos....Fortaleza, Brasil.

LORENZI, H. Plantas daninhas do Brasil. 3.ed. Nova Odessa: Plantarum, 2000. 116p.

LORENZI, H.; MATOS, F.J.A. Plantas medicinais no
Brasil: nativas e exóticas cultivadas. Nova Odessa: Plantarum, 2002. 544p.

MALAVOLTA, E. Manual de nutrição mineral de plantas. São Paulo. Ceres. 2006. 638 p.

MARTINS, E.R. et al. Plantas medicinais. 2. ed. Viçosa:UFV, Imprensa Universidade, 1998, 220p.

MARQUES, F.C. Análise da qualidade de sementes de marcela Achyrocline satureioides LAM. D.C. (ASTERACEAE). In: MING, L.C.; SCHEFFER, M.C.; CORREAA Jr, C.; BARROS, I.B.I.; MATTOS, J.K.A. (Coord.) Plantas medicinais, aromáticas e condimentares: avanços na pesquisa agronômica, Botucatu: UNESP/CAPES 1: 43-69. 1998.

NOVAIS, R. F. et al. Fósforo. In: NOVAIS, R. F. et al. (Ed.). Fertilidade do solo, Viçosa: UFV, 2007. p. 471-550.

PUHLMANN, J. et al. Inmunologically active metallicioncontaining polysaccharides of Achyrocline satureioides. Phytochemistry, Ohio, v.31, n.8, 31, 2617-2621. 1992.

RETTA, D.S. Optimization and validation of the quantitative assay of flavonoids in Achyrocline satureioides and A. flaccida. Latin American Journal of Pharmacy, Buenos Aires, v.30, n.7, p.1360-1365, 2011.

RETTA, D. et al. Marcela, a promising medicinal and aromatic plant from Latin America: A review. Industrial Crops and Products, Amsterdam, v. 38, p. 27-38, 2012.

SANTIN, J.R. et al. Antiulcer effects of Achyrocline satureoides (Lam.) DC (Asteraceae) (marcela), a folk medicine plant, in different experimental models. Journal of Ethnopharmacology, Netherlands, v.130,n.2, p.334-339, 2010.

SANTOS, C. C. dos et al. Effect of the application of chicken litter composts on chemical properties of a Typic Haplorthox soil cultivated with sorghum [Sorghum bicolor (L.) Moench]. Científica, Jaboticabal, v. 32, n. 2, p. 134-140, 2004.

SOUZA, K.C.B. et al. Influence of excipients and technological process on anti-inflammatory activity of quercetin and Achyrocline satureioides (Lam.) D.C. extracts by oral route. Phytomedicine, Stuttgart, v.14, n.2-3, p.102-108. 2007.

TAIZ, L.; ZEIGER, E. Fisiologia vegetal. 5. ed. Porto Alegre: Artmed, 2013. 719 p.

TORRES, P.G.V. Plantas medicinais, aromáticas e condimentares: uma abordagem prática para o dia-adia. Porto Alegre: Rígel, 2005. 144p. 